Jens Schröter

\title{
What is film? Points of contact between André Bazin and Chris Marker
}

\begin{abstract}
"A strange terminological confusion has arisen - between the execution and the integral nature - according to which a film is more or less of a film depending on its theme, although nobody would ever dream of saying that a painting was more or less of a picture depending on its subject-matter. What a paradox, an autonomous art form like painting is granted that freedom, while films are to be subjected to terror and purism. The longing to be a film and nothing but a film is perhaps only the first, larva-like emergence of the question: what if film does not exist? What if it were only a convenient collective term with which to refer to a new condition of older art forms..."
\end{abstract}

Chris Marker

The following reflections will focus upon one of Marker's early essays, "The Film of Tomorrow. An Apologia of the Wide Screen". ${ }^{1}$ It is no coincidence that Marker addresses marginal forms of film in his essays, such as animated films, ${ }^{2}$ amateur films, ${ }^{3}$ and the "subjective film". ${ }^{4}$ It is decisive that Marker's thoughts on film as in between or contrasted with other media and the resulting idea of what "film" is imply a model that acknowledges the inner heterogeneity of media. This may be one of the roots of Marker's openness to very different media and his tendency to produce "impure" films, such as films "contaminated" by video images, for example. As the most prominent exponent of film theory at this time was André Bazin, a systematic comparison of Marker's texts and selected essays by Bazin is instructive. Bazin, who already met Marker as early as 1946, is generally regarded as representative of an ontological, realistic concept of film that seems to conflict with Marker's intermedial approach. However, in many points Bazin's approach is in fact much more complex, so that it becomes possible to discern a deep affinity between the two.

"The Film of Tomorrow" is a defense of widescreen technology. Marker emphasizes that our focus should not be the rejection of new technological developments, claiming that they can

\footnotetext{
${ }^{1}$ Chris Marker, "Der Film von Morgen." Film s6 2 (February 1956): 67.

${ }^{2}$ Chris Marker, "Der Trickfilm." DOK 50 (1950): 75 f.

${ }^{3}$ Chris Marker, "Aus dem Bereich des Amateurfilms." Op. cit., 64.

${ }^{4}$ Chris Marker, "Der subjektive Film." Op. cit., $67 \mathrm{f}$.
} 
no longer be used to make "proper" films. Rather, we should be concerned with "encountering these new technical achievements trustingly" (FvM, p. 67). Here, we can see the programmatic impetus of the essay's title: film is not something that can be reduced to one single technical-aesthetic complex that exists at a particular point in time, it is rather in a constant state of becoming, ${ }^{5}$ both in regard to its technical basis and the stylistic forms that result from it, that is, everything from which we can deduce "being". The film of tomorrow always relocates and questions the film of today.

This initially seems to be a manifest difference to Bazin; after all, in his essay "The Ontology of the Photographic Image", 6 published in 1945, Bazin had deduced a "reality-function"7 of the photographic and thus also the cinematographic image from the technical structure of photography, from the causal link between image and reference through light and from its automatism. ${ }^{8}$ His line of argument starts with death: "death is but the victory of time" (WiC, 9). In his view, the history of representation starts with the embalming of dead bodies and culminates in photography and film "that satisfy, once and for all and in its very essence, our obsession with realism" (12). Capturing the human body in representation, in a "form that endures", as a kind of victory over "a second, spiritual death" (10) - over oblivion - is what has evoked this realism. Photography seems a kind of redemption (cf. 12), as it has made "objective" representation possible, which, freed from the "fee of an inescapable subjectivity", forces the viewer to "accept as real the existence of the object reproduced" (13, italics J.S.). Thus "it embalms time" (14), representing the "presence of lives halted at a set moment of their duration", even if these representations - as is the case with very old photographs - only consist of "grey or sepia shadows, phantomlike, almost indecipherable". In doing so, photography has liberated art from its "obsession with likeness" and is able to present the object - seen through the lens - "in all its virginal purity [...] to [...] love" (15).

The decisive factor here is that photography preserves the object beyond its real-life transience through "the transference of reality from the thing to its reproduction" (13).

\footnotetext{
${ }^{5}$ On this point, cf. André Bazin, "In Defence of Mixed Cinema." In What is Cinema? Vol. I (Berkeley: University of California Press, 2005), 53-75; on cinema's impermanence, cf. 74. (All articles taken from What is Cinema? are cited in the text with the abbreviation WiC and page numbers.)

${ }^{6}$ André Bazin, "Ontology of the Photographic Image" (1945). Loc. cit., 9-16.

${ }^{7}$ Cf. Gilles Deleuze, Cinema 2. The Time-Image (Minneapolis: University of Minnesota Press, 1997), 309 (footnote).

${ }^{8}$ On this, cf. David Brubaker, "André Bazin on Automatically Made Images." The Journal of Aesthetics and Art Criticism 51, no. 1 (1993): 59-67.
} 
Although Bazin initially emphasizes that today images are "relieved of their magic role" (10) and their "anthropocentric, utilitarian purpose", for him film remains "change mummified" (15). The technical images, on which no "shadow of doubt" (12) cast by a subjective hand falls, dissolve the "logical distinction between what is imaginary and what is real" (15): "Every image is to be seen as an object and every object as an image." Here Bazin returns to "the ontological identity of model and image" (10) which he reads as a mummification technique engaged in an endless attempt to defer death, and which he had pronounced dead at the beginning of his essay. Death closes the circle of his argument, death which Bazin uses to define photography. Bazin's interpretation of photography as the "the most important event in the history of plastic arts" (16), a history he sees as motivated by the "appetite for illusion" (11), constructs photography within the framework of a kind of positive eschatology. Bazin's choice of words - "form that endures", "spiritual death", "faith", "redeemed", "virginal", "love", "rescu[e] from corruption" and "liberation" from blindness - already point to his quasi-theological concept of the image. There is only one reproduction of an image in Bazin's text: the Holy Shroud of Turin, Christ's shroud, which Bazin actually refers to as "combin[ing] the features alike of relic and photograph" (14, footnote). He stresses that "[a]ll the arts are based on the presence of man", while "photography derives an advantage from his absence" (13): acheiropoietos! In his study on the history of cultic Christian art, Hans Belting elaborates: "In our present day, the comparison with photography suggests itself. For it is concerned not with art, the invention of an artist, but with the greatest possible truth of representation." ${ }^{9}$ Photography, whose inventor Niepce is referred to as a redeemer, creates images that possess "the irrational power [...] to bear away our faith" (14). These images allow us to gaze lovingly at objects that shine with a virginal radiance.

\footnotetext{
${ }^{9}$ Hans Belting, Bild und Kult. Eine Geschichte des Bildes vor dem Zeitalter der Kunst (Munich: Beck, 1993$), 66$. Incidentally, a trace of this theological conception can also be found in Roland Barthes' Camera Lucida (New York: Farrar, Straus and Giroux, 1981): “Always the Photograph astonishes me, with an astonishment which endures and renews itself, inexhaustibly. Perhaps this astonishment, this persistence reaches down into the religious substance out of which I am molded; nothing for it: Photography has something to do with resurrection: might we not say of it what the Byzantines said of the image of Christ which impregnated St. Veronica's napkin: that it was not made by the hand of man, acheiropoietos?" (82). Gertrud Koch, "Das Bild als Schrift der Vergangenheit." Kunstforum 128 (1994): 195, notes that Barthes "shares this religiously formulated theory of the photographic image as a relic with André Bazin. [...] It appears as if the young Bazin and the old Barthes drew on the same religious substance. [...] What Bazin and Barthes have in mind is founding ontological realism on faith."
} 
In the same way that Jesus establishes a covenant between God and humans in the Christian myth, photography creates a "natural image of a world that we neither know nor can see" (15). ${ }^{10}$ Bazin's theological metaphor reveals just how emphatically he derives photography's realistic destiny and function from its technical foundation. Thus it seems only logical that Bazin repeatedly stresses the "realism that is the essence of cinema". ${ }^{11}$ However, caution is in order: precisely because Bazin advocates a realistic concept of cinema, he is open to technological shifts on the way to "total cinema". ${ }^{12}$ At least he always emphasizes, arguing against Eisenstein, Pudovkin and Alexandrov for example, that the introduction of sound has by no means led only to "filming dramas". ${ }^{13}$ Rather, sound has "carried montage in the direction of realism" (WiC, 33). For Bazin, technological developments are subject to the film medium's realistic teleology. This suggests that if films are to satisfy this realistic determination, they not permitted to make any borrowings from literature or theater - they must remain "pure". If this were true, then Bazin would perhaps be one of the representatives of "terror and purism" (FvM, 7 f.) that Marker attacks so strongly. However, with Bazin the matter is far more complex. Not only does his discussion of deep focus (to which we will return) emphasize that this creates a "unity of image in space and time" (WiC, 35), something directly reminiscent of Aristotelian demands of theatre; speaking of Wyler's use of depth of focus, Bazin also says that deep focus has made it possible for Wyler to "convert [...] the screen into a dramatic checkerboard" (ibid.).

Marker understands technical shifts in a similar way as referring directly to the "most confusing questions [...] raised by film." One of these questions is the "inclusion of theater." Widescreen cinema forces Marker to "think of a smoother, available, limitlessly accessible theater, truly an invention of the art of printing for the theater." This chain of media leads Marker to the question of "why the concepts of theater and film have always been so closely related" $(F v M, 67)$, even though it would have been possible to link the film with the

\footnotetext{
${ }^{10}$ Cf. Paul Virilio, Die Sehmaschine (Berlin: Merve, 1989), 58: “The world, which was 'rediscovered' like an unknown continent, appeared at last in all its truth."

${ }^{11}$ André Bazin, "Theatre and Cinema" [1951]. In What is Cinema, vol. I (Berkeley: University of California Press, 2005), 86.

${ }^{12}$ Cf. André Bazin, "The Myth of Total Cinema" [1946]. In What is Cinema, vol. I (Berkeley: University of California Press, 2005), 17-22.

${ }^{13}$ Cf. Sergej M. Eisenstein, Wsewolod I. Pudowkin, and Grigorij W. Alexandrow, "Manifest zum Tonfilm." In Texte zur Theorie des Films, ed. Franz-Josef Alberstmeier (Stuttgart: Reclam, 1990), 45; Bazin, WiC, 78: "Filmed theater, however, does not begin with sound", and 60: "sound film does not mark the threshold to a lost paradise."
} 
fair - the location it was first performed - or with the circus (cf. WiC, 57). He does not believe that theater and film are linked through their common architecture, especially as such a view would understand film only as an offshoot of the theater, even though - as the quote preceding the present essay shows - it should be seen as a "collective term" that refers to "a new condition of older art forms" (FvM, 71). This shows that Marker is not concerned with a genealogy in which film only constitutes a continuation of theater by other means. Accordingly - thus Marker - the first films actually have nothing to do with theater. Here, too, we can detect a similarity between Bazin and Marker, for Bazin emphasizes that "adaptation, borrowing and imitation do not appear in the early stages [of cinema]" (WiC, 57), but only emerge at a later point when filmic forms were more fully developed. Thus it is logical that Marker sees the oft-cited "fidelity to the stage work" only as the "fidelity of a label", as a purely "formal fidelity": "Theater was to come only later, and not as the conqueror of this new form of representation [of film, J.S.], but itself conquered and transformed" (FvM, 67). As Bazin puts it: "Far from being a sign of decadence, the mastering of the theatrical repertoire by the film is on the contrary a proof of maturity" (WiC, 69). Incidentally, both Bazin and Marker agree that turning to theater often only constitutes "the path towards lazy complacency" (FvM, 67), the "slippery slope of the merely facile" (WiC, $55)$.

Marker's claim that "the filmed stage work fulfilled its theatrical purpose the more faithfully the more it subjected itself to forms of expression that were really cinematographic" (FvM, 68 ) is fully compatible with Bazin's assumption that the problem of filmed theater often lay in the fact that it restricted itself to the "childish error" (WiC, 114) of "photograph[ing] it" (ibid., 69). The conquering of which Marker and Bazin speak means that "fidelity [...] paradoxically [...] is compatible with complete independence from the original" (67). The concern is less with the adaptation of the subject-matter of a given drama and more with the adaptation of the piece itself, insofar as the dramatic text itself represents theater. In concrete terms, this means that film must exceed theater, "but only by going beyond it, by relieving it of its imperfections" (79), and: "Thanks to its mobility, it is now the camera that is responsible for the real unity of time and place" (91). A successful theater adaptation for film is thus marked by an "added measure of the theatrical", ${ }^{14}$ which does not lead the

${ }^{14}$ WiC, 93. Also cf. Deleuze, op. cit., 84. 
audience to forget "theatrical situations" (79) but rather underlines them, just as some films of paintings produce a "re-creation" ${ }^{15}$ of painting. One consequence of these reflections is that Bazin does not concur with the hypothesis that theater is distinguished from film by the live, physical presence of the actors. For this argument was always used to deny "filmed theater" its right to exist. Once again, it is photographic ontology, which creates "more than mere resemblance, namely a kind of identity", ${ }^{16}$ a "pseudopresence" (WiC, 97) of the filmed actor, which leads Bazin to ask (98): "What we lose by way of direct witness do we not recapture thanks to the artificial proximity provided by photographic enlargement?" The decisive factor is that the separation of "execution and [...] integral nature - according to which a film is more or less of a film depending on its theme", which is also criticized by Marker (FvM, 71), is also rejected by Bazin to the extent that he stresses that "[i]t is those who care the least for fidelity in the name of the so-called demands of the screen who betray at one and the same time both literature and the cinema" (WiC, 68). In the same way that some novels can be "ultracinematographic" (ibid., 64), film can be ultratheatrical.

This obviously raises the question of how the "specificity" of a medium such as film is to be understood, for if film is understood in this manner it obviously can no longer be modelled as a medium referring rigidly to its 'actual' territory. Marker and Bazin share a certain virtual image of film, which reveals similarities despite a number of differences between them: Marker sees a "drive towards movement", which "has been inherent in pictorial art since the days of the cave paintings" (FvM, 58). This means that there is a principle - this drive that appears in not only one medial form, but rather is something that permeates all (or at least several) art forms or media - albeit not always in the same way. This would constitute a form of intermediality that breaks open the idea of a "closed medium", a transmedial intermediality. ${ }^{17}$ This means that there are transmedial structures and forms, such as

\footnotetext{
${ }^{15}$ André Bazin, "Painting and Cinema." In What is Cinema? vol. I (Berkeley: University of California Press, 2005), 169.

${ }^{16}$ Bazin, WiC, 96. Also cf. Barthes, op. cit., 45: "is this not the sole proof of its [photography's, J.S.] art? To annihilate itself as medium, to be no longer a sign but the thing itself?"

${ }^{17}$ I am drawing on Lars-Henrik Gass, "Bewegte Stillstellung unmöglicher Körper. Über 'Photographie' und 'Film'." Montage/AV 2, no. 2 (1993): $69 \mathrm{f}$. Right at the beginning of his discussion of the relationship between photography and film, he notes as a methodical hypothesis, as it were: "We should no longer speak of two definable ways of being - photography on the one hand, film on the other - that share an ontological reference; rather, aesthetic relationships of proximity evolve on a transmedial level, as it were, in which a film might appear far more closely related to a musical composition than to another film, and a photograph far closer to a painting than another photograph. [...] In this line of thought, abstract media-related apriori, general distinctions drawn between 'photography', 'film', 'theater, 'painting', 'literature' and so on can be
} 
narrative, fictionality or perspective, which appear in various media and render these media comparable. However, this also means that media can never be completely separate but also have parallels with one another - something that is obscured by the talk of absolute differences between media: "If a 'medium' contains the structures and possibilities of another or other media, then this implies that the notion of isolated, monadic media or sorts of media can no longer be upheld."18 Bazin already argues along these lines when he points out that it is precisely the supposedly "pure" medium of cinema, celebrated by critics, that must be seen as modifying "the sense of theatricality in a performance" (113). However, it is even more decisive that Bazin identifies narrative structures or "dramatic structure[s]" (87) that cinema has "borrowed" for its own development of literature and theater. He also mentions the opposite case, where techniques have passed from film to literature. It is not only due to Bazin's awareness that borrowings and influences represent a constant throughout the history of art as a whole that he refrains from damning these borrowings of film from related art forms within the context of purism (cf. $71 \mathrm{f}$.). Rather, he realizes that if film is able to avail itself of a literary technique and does so, then there is no point is saying that film is now "literary", as this technique has now also become a filmic technique. Boris Eichenbaum already noted along these lines that "in light of film, many of literature's privileges have now lost their monopoly. [...] Like theater, by fructifying film and contributing to its development literature simultaneously lost its earlier status, and its continued evolution must take account of the existence of a new form of art." ${ }^{19}$ Marker's question concerning film, "What if it were only a convenient collective term by which to refer to a new condition of older art forms?" (FvM, 71), can be understood as meaning exactly this: with the emergence of film, the relations between the interrelated media, their "places within the system", shift and change. ${ }^{20}$ Techniques that until now were specific to literature or theater suddenly appear - perhaps even in exaggerated form - in film. Marker notes along these lines that film "perfects the conquests [of theater and painting, J.S.] with its own means" (FVM, 68). Traditional media lose their "monopoly" on the techniques

abolished in the use of aesthetic resources." On this, also cf. Jacques Aumont, "Projektor und Pinsel. Zum Verhältnis von Malerei und Film." Montage/AV 1, no. 1 (1992): 77-89.

${ }^{18}$ Jürgen E. Müller, Intermedialität. Formen moderner kultureller Kommunikation (Münster: Nodus, 1996$), 82$.

${ }^{19}$ Boris Eichenbaum, "Probleme der Filmstilistik." In Poetik des Films. Deutsche Erstausgabe der filmtheoretischen Texte der russischen Formalisten mit einem Nachwort und Anmerkungen, ed. Wolfgang Beilenhoff (Munich: Fink, 1974), 14.

${ }^{20}$ Friedrich Kittler, "Geschichte der Kommunikationsmedien." In Raum und Verfahren, ed. Jörg Huber and Alois Müller (Basel: Stroemfeld/Roter Stern, 1993), 188. 
specific to them, and accordingly they will need to be defined and specified differently in future: they enter into new conditions, for which the briefest collective term is "film". This shift is constant and neverending.

However, as we will see, in Bazin the expansion of film through literary and theatrical techniques ultimately remains tied to the "specific" reality functions of the cinematographic image ${ }^{21}$ as this a) material and ontological basis of the film should remain unaffected by the b) transmedial - that is, formal, narrative and stylistic - structures taken on by concrete films. ${ }^{22}$ Ultimately, these demands are irreconcilable: one cannot on the one hand assume an "original polyvalence" (WiC, 60), a purely relational specification, and on the other hand assert the realism of film as its immutable ontological foundation. Bazin repeatedly makes use of "dialectics" to unite these two levels. The dissolution of the "dialectic" between "cinematic realism and theatrical convention" (87) in Laurence Olivier's films shows that the "the success of filmed theater supposes that dialectical progress [has] been made with the cinematic form" (117). Bazin expects that it is precisely through the assimilation of the "elaborated subjects amassed around it by neighboring arts during the course of the centuries" that the "dialectic of the history [...] will restore [...] this desirable and hypothetical autonomy" (75) to the cinema. We will encounter the dialectic of montage and homogenous camera angles again in relation to "inner montage".

Here, however, we can note a clear difference to Marker's approach: while Bazin is concerned with transmedial techniques that have to be united "dialectically" with the ontorealistic mediality of film, Marker speaks explicitly of a material, medial "enclave" in the heart of theater, in which the transmedial "drive towards movement" manifests: in this sense, the performance practice of theater itself, its pragmatics, is already shot through with heterogeneous aspects, with zones of "cinematographic endeavor" (FvM, 68), which Marker locates in the device of the opera glass. ${ }^{23}$ Once again, he does not separate one of

\footnotetext{
${ }^{21}$ Cf. Deleuze, op. cit.

${ }^{22}$ This tension already crept into "Ontology of the Photographic Image", where Bazin states after establishing the ontological connection of film to photography: "On the other hand, of course, cinema is alse a language" (WiC, 16).

${ }^{23}$ Cf. B. Kazanskij, "Die Natur des Films." In op. cit., ed. Wolfgang Beilenhoff, 80: "And the opera glass, even though it does not enlarge, still brings the actor so close to today's audience members that the smallest details of his acting are sufficiently emphasized. However, the opera glass actually destroys the scenic effect by mechanically narrowing the scope of view and isolating one detail from the stage environment and the action as a whole."
} 
theater's essential traits from its "usage" or "implementation"; it is precisely in its "use", the use of the opera glass - a close-up, as it were - that he locates the "factor" through which "theater abdicates" (FvM, 68). While this can be reconciled with the relational shifts in the "system of the arts" discussed above, it is not compatible with Bazin's insistence on the transmediality of techniques while retaining ontological realism at the same time. Here, Marker is more radical than Bazin: his question "what if film does not exist?" (71) would probably have seemed preposterous to his contemporary.

With this in mind, a complementary reading of the "zone" in SANS SOLEIL (1982), the zone of videographically transformed images, seems apposite. Hayao's comment that the images are now no longer "the transportable and concrete form of a reality that is already unattainable" not only refers to the de-referentialization of the images that develop from these "only-images". It can also be understood as meaning that in this zone, a different medium - video - infiltrates film as an "enclave" and that the images now no longer - as was necessarily the case beforehand - refer solely to the reality of the cinematographic technique of image production. This zone "contaminates" the film, just as the opera glass had furnished/wounded the theater with a zone of "cinematographic endeavor". Cinematic images, the "concrete form" of the device, the institution cinema, now no longer are this concrete form, but have been "conquered and transformed" (ibid., 67). The black images in SANS SOLEIL and the long, completely black end credits of LE JOLI MAI (1963) take on a similar meaning, and as the "negation of film as photographic, as an image created by light" ${ }^{24}$ they are able to unsettle the seemingly unquestioned definition of a media ontology founded upon the photochemical basis of the filmic image: the filmic image as the inscription of light. What if someone drew on photographic paper using fixing solution and then exposed this to light - an image based on the inscription of light - but would we call it "photography" ? ${ }^{25}$ Conversely: a conceptual artist takes photographs with a closed lens cap, but subsequently applies exactly the same development processes as "normal" photos to the resulting images - these photos would not have recorded light, ${ }^{26}$ but would still be

\footnotetext{
${ }^{24}$ Wolfgang Beilenhoff, "Licht - Bild - Gedächtnis." In Gedächtniskunst. Raum - Bild - Schrift. Studien zur Mnemotechnik, ed. Anselm Haverkamp and Renate Lachmann (Frankfurt am Main: Suhrkamp, 1991), 453. ${ }^{25}$ Cf. Max Black, “Wie stellen Bilder dar?” In Kunst, Wahrnehmung, Wirklichkeit, ed. Max Black, Ernst H. Gombrich and Julian Hochberg (Frankfurt am Main: Suhrkamp, 1977), 123.

${ }^{26}$ Of course, this does not apply in that even the non-exposed negatives have to be exposed to light when turned into positives. However, media-ontological models of photography neglect to mention this second
} 
called "conceptual photography", following the "fidelity of a label" (FvM, 68). ${ }^{27}$ The fact that LA JETEE (1961/64) is made up only of stills is a further indicator of Marker's skepticism towards media ontologies. The standing image as the "interruption of movement" represents that "decisive instant when cinema seems to be fighting against its very principle, if this is defined as the movement-image". ${ }^{28}$ According to Peter Wollen, LA JETEE thus leads to the assumption that "movement is not a necessary feature of film." 29 This redefinition of "film" around the standing image (something that Roland Barthes also aspired to, albeit in another way ${ }^{30}$ ) "allows LA JETEE to exist." ${ }^{31}$ Bellour deduces correctly that prior essential definitions implied the existence of certain artefacts such as "proper" $(F v M, 67)$ films, while forms that do not correspond to the presupposed ontology are all too often pushed aside and excluded.

Marker links the abovementioned heterogeneity of the theater with yet another aspect: the activity or passivity of the audience. To do this, like Bazin (WiC, 88) he uses the examples of the Battle of Agincourt from Laurence Olivier's HENRY V. (1947) and Cocteau's LES PARENTS TERRIBLES (1948) (cf. ibid. 90-94). To an even greater degree than the parallels shown above, the parallels in the chosen examples suggest that Marker is referring directly to Bazin's discussion. Marker's reflections thus emphasize one of the traditional objections to film, namely that the way it filled the dramatic action with detail restricted the imaginative scope of the audience, and thus forced viewers into passivity, while the theater by contrast compelled the audience to become active through the "room [which theatrical presentation has] to maneuver between the audience's appetite and the physical possibilities of theater". Thus Marker is clearly reproducing the binary of opposition - identification that Bazin identifies in the texts of Rosenkrantz. "Opposition" corresponds to the audience's active attempts to ascribe a fictional existence to the actors standing in front of them in the theater. Bazin summarizes Rosenkrantz: "The cinema calms the spectator, the theater

exposure. They only ever mention the first exposure, which denotes the indexical connection between the prephotographic object and its image. This connection is abolished in a radical way in the example given.

${ }^{27}$ Cf. Jens Schröter, “Der Name der Fotografie." 703 Magazin 1 (1996): 31-33.

${ }^{28}$ Raymond Bellour, "The Film Stilled." Camera Obscura 14 (1990): 99. For Bazin, too, film is "change mummified" (15). The fact that LA JETEE is not mentioned in Deleuze's otherwise detailed books on cinema may also be due to this fact, given that Deleuze sees "movement" as the cinematic image's "most authentically visible characteristic" (Deleuze, op. cit., 27).

${ }^{29}$ Cited in: ibid., 100.

${ }^{30}$ Roland Barthes, "The Third Meaning." Image - Music - Text (London: Fontana, 1977), 52-68.

${ }^{31}$ Bellour, op. cit., 100. 
excites him" (ibid., 99). However, Bazin is not content with this contrast. Rather, he stresses: "it is a fact that the cinema has at its disposal means which favor a passive position or on the other hand, means which to a greater or lesser degree stimulate the consciousness of the spectator" (ibid., 100). While this dichotomy of presentation options is already familiar, Bazin makes a distinction between various forms of montage - from the "insidious" (39) and "analytical" to "montage by attraction" - as well as clearly distinguishing between expressionist images and the "dialectical step forward in the history of film language" (35) made possible by deep focus. While the different forms of montage project meaning "onto the field of consciousness of the spectator", "impos[ing the] interpretation of an event on the spectator" (26), thus "by [their] very nature rul[ing] out ambiguity of expression", deep focus "reintroduce[s] ambiguity into the structure of the image" (36). Deep focus, as seen for example in the work of Jean Renoir or Orson Welles, "brings the spectator into a relation with the image closer to that which he enjoys with reality" (35), which implies a "more active mental attitude" and "a more positive contribution on his part to the action in progress" (35-36). In brief: Bazin's deep focus realism is a realism of the active audience engaged in interpreting the ambiguity of reality. The space visible in the film, as a cache, ${ }^{32}$ is only a moving excerpt of the larger space that can, in principle, become visible from the off at any time. And we as spectators can always actively anticipate what will become visible next. The more likely our guess, the more realistic the film: ${ }^{33}$ for Bazin, the realism of film is mainly the "realism of space" (WiC, 188). The sequence shot as the active exploration of a previously existing quasi-theatrical space, homogenous in terms of place and time and in which the actors can in principle move independently of the camera, corresponds to our activity of exploring reality. ${ }^{34}$ For "[t]he camera is at last a spectator and nothing else" (WiC, 92). ${ }^{35}$ Here a further point in which Marker and Bazin overlap becomes evident: the rejection of radically subjective film, as realized for the first and only time in THE LADY OF THE LAKE (1946, Richard Montgomery). Marker criticizes this - in Bazin's words - "puerile"

\footnotetext{
${ }^{32}$ Cf. Bazin, WiC, 165.

${ }^{33}$ Cf. Edward Branigan, "What is a Camera?" In Cinema Histories, Cinema Practices, ed. Patricia Mellenkamp and Phillip Rosen (Frederick: University Press of America, 1984), 98.

${ }^{34}$ Cf. Deleuze, op. cit., 105: "Here time became out of joint and reversed its dependent relation to movement; temporality showed itself as it really was for the first time, but in the form of a coexistence of large regions to be explored."

${ }^{35}$ On the anthropomorphism of the camera in Bazin, cf. Branigan, op. cit., 92.
} 
experiment, stating that the careful observation of a face in a "good old close-up" ${ }^{36}$ says far more about the protagonists' subjective condition. The camera takes on the point of view of a "witness" (WiC, 92). But Marker's criticism of the alleged passivity of the cinematic audience goes even further: it shows that the same accusation could also be levelled at the theater, namely from the point of view of the novel, which demands even more imaginative effort (as it is provides even less detail). ${ }^{37}$ Marker continues this line of argument - via poetry and music - to reach its ultimate conclusion, namely that the audience would be able to attain the highest, most complete and most free form of imagination if they were confronted with "silence" (FvM, 69-70), with an utter void: "Ultimately, this idealistic line of thought culminates in the notion that the spectator already possesses total and pre-existent knowledge, which requires only discreet maieutics to see that which it already knew of eternity revealed before it" (69). ${ }^{38}$ His criticism of what ultimately is a Platonic model of meaning construction, in which the ideal meaning precedes its material expression, culminates in his claim that in this case the "world of drama has been in the spectator's possession from the beginning". In reality, a radically passive, anamnetic model of the spectator thus forms the foundation of the traditional theory of imaginative freedom, of the "world of consciousness". Human beings' "original consciousness", which simply "is" in a quasi-monadic manner, thus contains all imagination in potential and only needs to actualize it according to the scope granted by a given media presentation, as if through a "gland" as a kind of "mental excretion".

This is opposed by the "original emptiness" of the spectator who always "conquers" the drama afresh "down to the smallest detail" in a neverending process of becoming. In this "world of action", there is a constant "adaptation of the inner eye to the given circumstances". However, this "adaptation" is not passive - as it is an adaptation to "foreign and, in a certain sense, unimaginable" objects, the spectator is in a permanent process of transcending and overwriting him- or herself. This spectator is the human being "who creates himself". This surprising use of the opposition between active and passive leads Marker to observe concisely that here "the function of the imagination [changes] its meaning". In this sense, it is only logical that "reality is more surprising than fantasy", given

\footnotetext{
${ }^{36}$ Marker, "Der subjektive Film." Op. cit., $67 \mathrm{f}$.

${ }^{37}$ Bazin also discusses the novel, cf. WiC, 110.

${ }^{38}$ All following quotes in the main text are taken from this page unless indicated otherwise.
} 
that "reality" is here understood as an exterior, a quality of difference that repeatedly and irritatingly invades consciousness and forces it to change its structure, while fantasy is the realm of déjà $v u$, déjà $l u$, in which the familiar can be permutated and recombined but radical breaks and openings are never possible. Accordingly, the "most encouraging function of drama" can only be the "reinvention" - not the representation - of reality, understood as a "construction of the coincidental", as a contingent ${ }^{39}$ quality of difference that forces the audience to actively engage in self-change. ${ }^{40}$ The seemingly paradoxical expression "construction of the coincidental" leads us to yet another point at which Bazin and Marker could be seen to meet. For Bazin, too, who was of course well aware that realism cannot mean the reflection of reality as such a reflection would be impossible given the overabundance of the real, realism was only possible as an aesthetic "reinvention". Bazin is certain that there can be no realism in art that is not foremost profoundly aesthetic. ${ }^{41}$ Hence the aforementioned "function of theatricality" of deep focus. ${ }^{42}$ As the space opened up by deep focus and the sequence shot needs to be understood within the context of the "unity of image in space and time" as a homogenous, quasi-theatrical space, the director needs to construct this unity in the dimension of depth through constructing a "dramatic checkerboard" (WiC, 35). ${ }^{43}$ Filmic realism does not deny montage. Rather, it integrates it into the shot "dialectically" as an "inner montage": "Objects and characters are related in such a fashion that it is impossible for the spectator to miss the significance of the scene" (35-36).

According to these reflections, the only possible conclusion not only for Bazin, but also for Marker, is: "This is why film's various realistic capabilities, such as image, color, depth, tend to have the effect of increasing the audience's activity" (FvM, 69). While this theory corresponds to Bazin's claim that the increased realism of deep focus (and sound) grant the spectator a greater degree of activity, Marker is more radical than Bazin in the entire

\footnotetext{
${ }^{39}$ Cf. David Wellbery, “Die Äußerlichkeit der Schrift.” In Schrift, ed. Hans-Ulrich Gumbrecht and Karl Ludwig Pfeiffer (Munich: Fink, 1993), 337-348. Wellbery points out the significance of contingency for the entire field of the aesthetic.

${ }^{40}$ Kaja Silverman, The Threshold of the Visible World (New York: Routledge, 1996), 185, notes on SANS SOLEIL: "It would, in short, introduce the 'not me' into my memory reserve."

${ }^{41}$ Incidentally, Bazin's "aestheticism" was strongly criticized by the Leninist and Stalinist Left. Marker defended Bazin against these attacks. Cf. Dudley Andrew, André Bazin (Oxford: Oxford University Press, 1990), 137.

${ }^{42}$ Deleuze, op. cit., 109.

${ }^{43}$ The checkerboard refers to a popular way of demonstrating depth in perspective - whether as a coffered ceiling in many paintings, or literally as the checkerboard pattern of the stage in baroque theater.
} 
passage discussed. While Bazin aims to level the difference between theater and film ${ }^{44}$ by pointing out that films also have presentation strategies that encourage activity (in a similar way to his criticism of the advantage of the live presence of the actor in the theater), Marker reverses this hierarchy and in his critique of the model of meaning construction emphasizes that the film requires more activity the more realistic it is.

The debate sketched above on "whether imagination is a gland or an eye" (FvM, 70) according to Marker has "the merit of presenting in its proper light the fundamentally double nature of film and the imperative on which it is based in want of laws." He now stresses that the field of "film" is itself heterogeneous, both in its "execution" and concerning the "studies, [...], methods of analysis, [...], research" that circulate on it: "The most blatant empiricism still governs both the study and the creative work of film". This means that a wealth of heterogeneous practices and discourses constitute the field of "film", that it is shot through with "theatrical", "painterly" 45 etc. zones and that there are constant battles over how to define it. ${ }^{46}$ Its "creators have left a certain number of tricks and recipes as their legacy, which are received like a grammar and in reality are not even an orthography." Seen in this way, there would be no essential language of film, which possibly suggests why later attempts to construct a semiotic theory of film were doomed to fail. ${ }^{47}$ "What a paradox, an autonomous art form like painting is granted that freedom, while films are to be subjected to terror and purism" (FvM, 71). Within the context of the present reflections, the freedom of which Marker speaks here can be understood as freedom from the terror of purism, from the normative demands of ontological media theories. He emphasizes "that the concept of freedom can only be understood if the limits of freedom are defined beforehand", that is, every call to restrict a medium to its "proper" terrain provokes transgression. ${ }^{48}$ In Marker's text, the history of painting, whose "autonomous" phase in the 20th century can also be seen as the history of its permanent revolt against media specifics, serves as a role model for film. Incidentally, we can see a further point of contact with Bazin here, too, as Bazin repeatedly emphasizes that the invention of

\footnotetext{
${ }^{44} \mathrm{Cf}$. WiC, 100: "Thus theater and cinema will no longer be separated off by an unbridgeable aesthetic moat [...]." All following quotations are taken from the same page.

${ }^{45}$ On this, cf. Marker's essay on animated film (cf. footnote 2).

${ }^{46} \mathrm{Cf}$. Bazin, "What do we actually understand by the term 'film' in connection with the problem of interest to us here?"

${ }^{47}$ On this, cf. Deleuze, op. cit.

${ }^{48}$ Marker, "Der Trickfilm." Op. cit., 75.
} 
photography has liberated painting from "obsession with likeness", from everything that "was aesthetically least essential to it" (WiC, 15 and 119). If painting has now been freed from that which was "least essential" to it, then this suggests that it has now found what is "most essential" to it. This is very much in line with the Zeitgeist of the 1950s, and thus Marker's comparison was double-edged particularly at the time he made it, seeing as "terror and purism" were very much at work in the painting sector in the $50 \mathrm{~s}^{49}$ Clement Greenberg, convinced that "the unique and proper area of competence in each art coincided with all that was unique to the nature of its medium" declared in his "new Laocoon" that flatness was the "pure" medium of painting, which is why more or less nothing apart from abstract expressionism was tolerated as painting at this time: and inevitably new movements against this arose in the 1960s, such as pop art or nouveau realisme. $^{50}$

Once again, we see a strange tension emerging in Bazin's work. The intervention of a foreign medium - photography - liberates painting, making it possible for it to become itself. One the one hand, we can note a similar process to that discussed above in reference to transmediality. Photography appears, "takes on" a technique of painting, namely the naturalistic representation of what is visible, for example in line with the rules of centralperspective foreshortening. Thus it takes the very thing that up to this time was specific to painting away from it. Accordingly, it is actually not quite precise when Bazin states that "likeness and anecdote" were least essential to painting: far from it, they were most essential to it, in comparison to literature for example, and only became unessential because photography had broken painting's monopoly on likeness. ${ }^{51}$ But why should this relinquishing of likeness now reveal the "essence" of painting? Would it not be more appropriate to say that painting has simply become different, rather than more essential? It would appear that the true reason for this has already been touched upon above: as Bazin

\footnotetext{
${ }^{49} 1956$ was the year that Jackson Pollock died.

${ }^{50}$ Clement Greenberg, "Modernist Painting." In Modernism with a Vengeance. Collected Essays and Criticism, vol. 4 (Chicago: University of Chicago Press, 1995). The title of Greenberg's essay "Towards a newer Laocoon" suggests an elective affinity with Lessing's Laocoon, who is perhaps the forefather of all theories of media specificity. Cf. Clement Greenberg, "Towards a newer Laocoon." In Perceptions and Judgments. Collected Essays and Criticism, Vol. 1 (Chicago: University of Chicago Press, 1988), 23-37.

${ }^{51}$ This should not be taken to imply that painting can be reduced to this. The shifts that photography entailed here can be inferred from the fact that, following the invention of photography, the whole area of portraiture and its socioeconomic functions were taken over by the new technique. Cf. John Tagg, "A Democracy of the Image: Photographic Portraiture and Commodity Production." In The Burden of Representation. Essays on Photographies and Histories, ed. John Tagg (London: Macmillan, 1988), 34-59.
} 
refuses to relativize his assumption of a photo-ontological realism despite his insights into the reciprocal, relational references between media, he is forced to imply that other media are essentially different from the photographic medium in precisely this aspect. And accordingly "likeness" must be an unessential additional element of painting (and must always have been, in line with the "essence" of painting). It is only logical that Bazin once again uses dialectics in order to resolve the tension between relationality and essentiality: "Faced with photography, they [painters, J.S.] opposed it in the only valid way, by a dialectical enriching of pictorial technique" (WiC, 119).

In summary: there appears to be a key difference between Bazin and Marker in that Bazin, despite realizing the "original polyvalence" $(\mathrm{WiC}, 60)$, that is, the irreducible interwovenness of different media, nevertheless adheres to essentialist definitions of these media, especially the photo-ontological realism of film. By contrast, Marker's early texts contain no direct reference to this kind of photorealism, despite their significant affinity to Bazin in many other points. This perhaps explains why Marker turned not only to film, but also, in all "freedom" (FVM, 71), to literature, video and computer images. What do LA JETEE, SANS SOLEIL and LEVEL 5 (1996), what do JUNKOPIA (1981), LE FOND DE L'AIR EST ROUGE (1977) and lastly his new CD-ROM IMMEMORY (1997) have in common? Perhaps simply the fact that they are made by "Chris Marker". And perhaps this name is also a collective term. 